\title{
Analytical Information from Mass Spectrometry, Past and Future
}

\author{
Fred W. McLafferty \\ Department of Chemistry, Baker Chemistry Laboratory, Cornell University, Ithaca, New York, USA
}

\begin{abstract}
Two basic reasons are proposed for the tremendous success and future promise of mass spectrometry: (1) the unusually high volume of data obtainable from unusually small samples and (2) the success in converting these data into structural and quantitative information. The ion abundance dimension of mass spectrometric data is remarkable in its pico-to-attogram sensitivity and $>10^{6}$ dynamic range, and the mass scale dimension is uniquely high in the number of resolution increments for larger molecule ionization and high resolution. Additional dimensions of data arise from chromatographic coupling to mass spectrometry and tandem mass spectrometry, as well as from alternative ionization and ion reaction methods. Converting these data into chemical information is equally important. Past progress in these areas has been cyclical; for the immediate future a greater research emphasis is urged to convert data to information through better understanding of the relevant chemistry and better utilization of modern computer methods. ( $/$ Am Soc Mass Spectrom 1990, 1, 1-5)
\end{abstract}

$\mathrm{M}$ ass spectrometry has undergone amazing growth over the last four decades. Possibly a perspective examination of this can provide guidance for similar growth in the future. The basic utility of mass spectrometry has been its wealth and diversity of structural and analytical information [1-5]. For its growth, both past and future, two basic methods are proposed: increasing the amount of data while decreasing the sample size required, and increasing the capabilities to convert these data into scientific information, mainly through improved understanding of the underlying chemistry and application of modern computer techniques.

Certainly a hallmark of this progress has been the high creativity of, and unusual communication between, scientists in diverse areas doing both basic and applied research in academic, government, and industrial laboratories. Breakthroughs on fundamentals of ion optics, kinetics, ionization processes, and mechanisms have contributed to and depended on developments in reference data, instrumentation, and computer utilization, all of which have inspired unique applications in physics, geology, chemistry, biology, medicine, and environmental sciences. The basic chemistry found for small gaseous ions has led to mechanistic rationalizations placing the mass spectrometric structural elucidation of small molecules

\footnotetext{
* Presented at the 37th ASMS Conference on Mass Spectrometry and A] lied Topics, Miami Beach, Florida, May 24, 1989.

Address correspondence to Fred W. McLafferty, Department of Chemistry. Baker Chemistry Laboratory, Corncll University, Ithaca, NY 14853-1301. USA.
}

on a firm footing [1-5]. Extension to larger species was made possible by exciting developments in instrumentation for the ionization of increasingly large molecules, even those above 100,000 daltons [6-10]. The combination of mass spectrometry with chromatographic separation methods now accounts for the majority of analytical applications, while tandem mass spectrometry (MS/MS) makes possible further new dimensions of information [11, 12]. As with gas chromatography/mass spectrometry (GC/MS) interfacing, MS/MS requires new methods to convert the massseparated ion species into characteristic new masses for the next mass spectrometric separation, while a multiplicity of such steps $\left(\mathrm{MS}^{n}\right)$ brings additional problems of sensitivity and instrumentation requirements. However, the additional $\mathrm{MS}^{n}$ structural information gives promise for extended characterization of the unusually large molecules that can now be conveyed into the gas phase and ionized. Finally, automating the analytical process to take advantage of the unusually high information density of mass spectrometry and its comprehensive collections of reference data makes direct use of the astonishing new capabilities of the computer revolution.

\section{Volume of Analytical Data}

\section{One-Dimensional Data}

A few decades ago, analytical methods were mainly unidimensional; one measurement (e.g., volumetric or gravimetric) could yield the desired analytical infor- 


\section{Single Dimension Analysis}

$$
\begin{array}{l|l}
\begin{array}{l|l}
\text { response/ } \\
\text { molecule; }
\end{array} & \begin{array}{l}
\text { itrant, mI } \\
\text { precipitate, mg } \\
\text { refractive index }
\end{array} \\
\begin{array}{l}
\text { dynamic } \\
\text { range }
\end{array} & \begin{array}{l}
\text { tronsmittance (blue) } \\
\text { MS }
\end{array} \\
\text { Sensitivity: } 10^{-12}-10^{-18} \mathrm{~g}
\end{array}
$$

Figure 1. One-dimensional analytic data. Utility depends on sensitivity and dynamic range.

mation if sufficient specificity was provided by the preceding chemical treatment (Figure 1). Here the single-ion detection capability of mass spectrometry can provide enviable results for molecular samples. Picogram sensitivities are now commonplace in molecular mass spectrometry, and modern carbon-14 dating of 100,000-year-old samples in milligram quantities requires measurements at the attingram $\left(10^{-18} \mathrm{~g}\right)$ level. (Note that for such measurements to be classified as unidimensional, the instrumentation for any necessary separation of the measured ion must be considered the counterpart of the preliminary chemical treatment of the volumetric/gravimetric analyses.) In many cases, ion signals are also linear versus amount over a wide dynamic range, such as $1-10^{6}$ [13], with minimal matrix effects, representing an unusually favorable "Beer's law" response.

\section{Two-Dimensional Data}

The analytical revolution brought about by spectroscopic and chromatographic methods reflects their basic advantage of measurements in two dimensions, reporting absorbance, intensity, or abundance values at a multiplicity of wavelengths, retention times, or masses. The especially impressive gain in data volume this brings to mass spectrometry (Figure 2) is determined by the number of individual masses for which such measurements can be made. These "resolution increments" depend on both mass range and resolution. In recent years the mass range capabilities have grown tremendously, with several research groups now reporting ionization of molecules of molecular weight exceeding 100,000 [6-10]. The best resolution of a commercial instrument is provided by the Fourier transform (FT) mass spectrometer [14-16], with values of $3 \times 10^{6}$ at $\mathrm{m} / \mathrm{z} 100$ and $3 \times 10^{5}$ at $\mathrm{m} / \mathrm{z} 1000$ with heterodyne measurement over a limited mass range. The utility of this resolution is limited by the exact masses possible from combinations of the component isotopes of the molecular and fragment ions in the mass spectrum. For example, the current database [17] of 118,000 different compounds contains 25 different molecular formulas of nominal molecular weight 100 , but their exact mass values occur only between 99.930 and 100.125. The whole database contains 35,734 molecular formulas, so for EI spectra the resolution increments

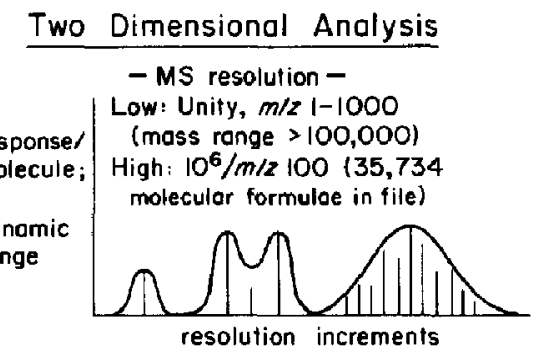

Figure 2. Two-dimensional data. Utility also depends on the number of resolution increments.

possible even under the best experimental conditions are probably $\sim 10^{6}$.

\section{Multiple-Dimension Systems}

One of the most exciting areas of mass spectrometry expansion has been into three and more dimensions of analytical data. The pioneering effort of this was GC/MS, first made into a usable system by Roland S. Gohlke [18], one of my first colleagues in the Spectroscopy Laboratory of the Dow Chemical Company. This system was based on our homemade gas chromatograph and a 1955 Bendix time-of-flight instrument. The latter's speed and sensitivity were critical to producing this extra dimension of the data (Figure 3), as were the clever interface designs of Ryhage and the Stenhagens and of Watson and Biemann. This has been followed by coupling the mass spectrometer to the high-performance liquid chromatograph and recently to many other forms of chromatography. Tandem mass spectrometry could be considered the first multidimensional method, based on the early observations of "secondary rays" by Sir J. J. Thomson [19, 20], but its real potential was realized only recently $[11,12]$. The millisecond or microsecond times for mass separation make feasible further dimensions $\left(\mathrm{MS}^{n}\right)$ and the combination of chromatography with MSiMS.

\section{Alternative Ionization and Ion Reaction Methods}

Valuable additional data became available from mass spectrometry with the utilization of ion chemistry in addition to the classical unimolecular dissociations of

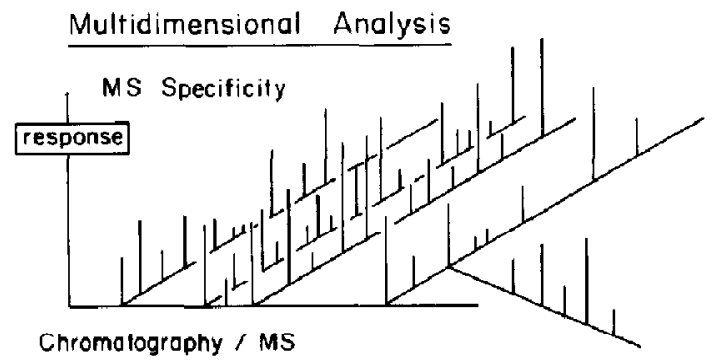

$M S / M S, M^{n}, C^{\prime} / M^{n}$

Figure 3. Multiple dimensional data. Resolution increments of additional dimensions yield exponential increases in data. 
molecular ions formed by electron bombardment. A wide variety of techniques, starting with chemical ionization, employ ion-molecule reactions that can minimize molecular dissociation and rearrangements and provide additional structural characterization. Similarly, for MS/MS a variety of techniques can now be employed for the dissociation and reaction of massseparated primary ions of low and high kinetic energies. Dissociation of large (masses $>3000 \mathrm{u}$ ) ions has been a serious problem; very recent results [21, 22] indicate that multiply charged ions are much more amenable to dissociation. Neutralization-reionization mass spectrometry [23-26] and charge-remote fragmentation [27] even make possible the use of the unimolecular dissociations of neutral species, which can substantially decrease interfering isomerizations [28] as well as provide new dissociation chemistry (see below).

\section{Instrumentation and Data Handling}

Advances in instrumentation have been fundamental to progress in mass spectrometry. Improvements in resolution, mass range, large-molecule ionization, and data acquisition and reduction are obvious landmarks to progress, with advances in instrument reliability and "user-friendly" operation of even greater importance to many spectrometrists. Combinations of these new techniques show great promise; for example, electrospray ionization $[9,10]$ is effective for peptides of molecular weight $>100,000$ that form ions with $>100$ charges; for such $m / z$ values of about 1000 the FT instrument has a resolving power greater than 100,000 , giving the possibility of unit resolution for such largemolecular spectra [29].

However, efficient utilization of these multidimensional capabilities has attracted new attention to the importance of multichannel detection. Array detectors acquiring ions simultaneously over even a few percent of the mass range [30] will provide more than an order-of-magnitude sensitivity increase for a spectrum of 1000 resolution increments, and ion storage instruments (FTMS, ion trap) can measure the entire spectrum (e.g., $m / z$ 90-16,000 [31]) of ions produced in an ionization pulse. A proposed Hadamard transform method [32, 33] even provides multichannel detection for MS/MS (and, in principal, MS $^{n}$ ) spectra with such ion storage instruments. For example, to measure the secondary mass spectra from dissociating 100 mass values of primary ions, SWIFT [34] is used to select ions representing 50 values to be transferred to the other ion cell of the dual-cell FT instrument; the ions in both cells are dissociated, and the products are measured to subtract the signals of one cell from those of the other. This process is repeated 100 times (requiring 1/100 as much sample as individually measuring the $100 \mathrm{sec}-$ ondary spectra with the same signal-to-noise ratio), and the data are used in 100 simultaneous equations to generate the 100 individual secondary spectra [33].

\section{From Mass Spectrometric Data to Chemical Information}

Volumes of data are useless if they cannot be converted into the desired information. As a chemist, one of the most rewarding aspects of mass spectrometry has always been that the most critical requirement for this conversion is a basic understanding of the chemistry involved. The initial emphasis was on the unimolecular dissociation of singly charged cations, and this was followed by exploitation of the bimolecular chemistry of cations and the chemistry of anions, multiply charged ions, and neutral species. A fortunate difference from conventional chemistry is that most of the basic data concerning unimolecular cation reactions are numerical, not bibliographic; thus, modern computer science is a powerful ally in the development and utilization of this chemistry.

\section{Computer Algorithms for Retrieoal and Interpretation}

The most comprehensive early effort to collect and evaluate reference spectra supplied by mass spectrometrists worldwide was made in collaboration with Einar Stenhagen and Sixten Abrahamsson [35]. Since their untimely deaths, the great majority of the current database of 140,000 different mass spectra of 118,000 different compounds has been collected at Cornell [17]. Gerard Salton, professor of computer science at Cornell, has been a key figure in developing statistical methods for document retrieval from libraries [36]. These principles were adapted for the ProbabilityBased Matching (PBM) algorithm [37, 38], which has undergone many improvements in the last fifteen years (Figure 4). Salton has shown that reliable evaluations of retrieval performance must be two-dimensional; from about 400 randomly selected "unknowns," such "recall/reliability" plots [39] show that even early versions of PBM were superior to any other available retrieval algorithm. If the unknown compound is not in the reference file, of course, PBM should show no promising retrievals; such an unknown then requires interpretation, for which the Self-Training Interpretive and Retrieval System (Figure 5) has been developed as an aid $[38,40]$. This is cited as one of the first artificial intelligence systems of broad applicability to a scientific field.

\section{PROBABILITY BASED MATCHING Reverse Search}

$\begin{array}{ll}\text { Occurrence Statlstics: Mass, Aburidunce } & (1974) \\ \text { Flagged peaks, } \mathbf{M}^{+} \text {, etc.; Reliability Fanking } & (1977) \\ \text { Tilting, quadratic scaling } & (1980) \\ \text { Spectrum subtraction (1979), forward search } & (1985) \\ \text { Weighted file order: } 2 \text { s search (PC, } 9 \text { s) } & (1981) \\ \text { Exact mass unknown, unit resol. reference } & (1989) \\ \text { Compensene other Markovian statistics } & (1990 ?)\end{array}$

Figure 4. Improvements in the Probability Based Matching algorithm. 
ARTIFICIAL INTELLIGENCE (1973)

Self-Training INTERPRETIVE \& Retrieval System

Supervised leaming: 26 data classes

Parametric: large data base (tast learnep)

Molecular Wh.: $92 \%$ first, $95 \% 1^{\text {st }}$ or $2^{\text {nd }}$

587 Substructures, reliablity value

Maximal Common Substruature

(\$low; fast processor, 1990?)

Figure 5. Improvements in the Self-Training Interpretive and Retrieval System.

\section{Understanding Ion Chemistry}

In its early years, mass spectrometry was plagued with a discouraging reputation concerning its capabilities for molecular structure elucidation. The quasi-equilibrium theory developed by Eyring and his students [41, 42] demonstrated that mass spectra follow basic principles of chemical kinetics, but the conversion of organic chemists to mass spectrometry probably began when they were shown that unimolecular ion reactions were logical according to commonly accepted chemical principles. 'I'he ubiquitous tendency to form stable product ions was shown in a dramatic fashion by Meyerson in his historic characterization of the tropylium ion [43], and the demonstration that many rearrangement reactions could be explained and predicted by specific, logical mechanisms $[44,45]$ did a great deal to remove the superstition that rearrangements were the fatal flaw of mass spectrometry. Especially gratifying has been the fact that mass spectrometrically derived chemistry of ions has found important applicability to other ion reactions, such as those of electrochemistry and radiation chemistry and in media such as "magic acid" and plasmas [46-49]. Our understanding of these reactions has been greatly increased by molecular orbital calculations [50] and special experimental studies such as nonergotic dissociations [51] and stepwise versus concerted rearrangements $[52,53]$.

\section{Overcoming the Inadequacies of Ion Chemistry}

Some of the most interesting research areas of mass spectrometry in the future will involve discovering new chemistry to overcome the inadequacies of unimolecular cation dissociations for important structural and analytical problems. For example, hydrocarbon and other types of cations usually rearrange much more readily than their neutral counterparts; thus, the EI and collisionally activated dissociation mass spectra of isomers such as 1- and 2-butene [45] are closely similar. Here, a general approach is to change the chemistry-for example, to that of the corresponding neutral species. Charge-remote fragmentation [27, 54] and neutralization-reionization (NR) mass spectrometry [23-26] appear to be particularly promising [28, $55]$ in this regard (Figure 6). A special bonus of these NRMS studies has been in the formation and char-

\section{NEUTRALIZATION-REIONIZATION MS}

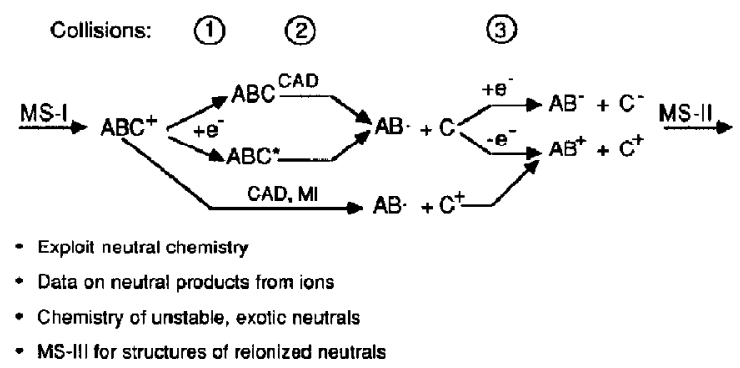

Figure 6. Attributes of neutralization-reionization mass spectrometry.

acterization of unstable exotic neutral species such as antiaromatic molecules [55], radicals, carbenes, enols, zwitterions, ylides, and hypervalent species [26]. To prepare such neutrals it is only necessary that the corresponding cation or anion be stable. An especially promising technique is the MS/MS/MS characterization of the relative free energies of the isomerization and dissociation reactions of such neutrals. Energy for such reactions is added to the fast neutral species by collision, the neutral products are reionized, and the resulting ionic products are mass analyzed in MS-II, with isomeric characterization through collisional dissociation and MS-III mass separation [26, 56-58].

\section{Future}

In a generation or so of mass spectrometry, we have gone from having the reputation of "no real chemistry there" to being recognized as a vital source of uniquely new chemistry. The current research interests in the field as shown by publications and meeting papers, however, would appear to place a much heavier emphasis on applications. Judging by past progress in the field, the users of the technique should remember that improved utilization is fundamentally limited by our chemical understanding of mass spectrometric processes. A prime professional responsibility of a mass spectrometrist is to keep abreast of, and contribute to, progress in this basic chemistry. Further, there appears to be even less awareness of computer techniques for retrieval and interpretation of these data, even though these techniques are surely required for the efficient utilization of the unique data volume of mass spectrometry. With the explosive expansion of mass spectrometry to the study of really large molecules, we can look forward to uncovering new information on their chemistry, making further contributions of value to other areas such as biology and medicine.

\section{Acknowledgments}

This work was made possible by the help of uniquely talented students and co-workers and the generous financial support of the National Institutes of Health and the National Science Foundation. 


\section{References}

1. Beynon, J. H. Mass Spectrometry and Its Applications to Organic Chemistry; Elsevier: Amsterdam, 1960.

2. Biemann, K. Mass Spectrometry: Organic Chemical Applicntions; McGraw-Hill: New York, 1962.

3. Budzikiewicz, H.; Djerassi, C.; Williams, D. H. Mass Spectrometry of Organic Compounds; Holden-Day: San Francisco, 1967.

4. McLafferty, F. W. Interpretation of Mass Spectra, 3rd ed.; University Science Books: Mill Valley, CA, 1980.

5. Gross, M. L. Mass Spectrom. Rev. 1989, 8, 165-197.

6. Macfarlane, R. D. Anal. Chem. 1983, 55, 1247a-1264a.

7. Barber, M.; Bordoli, R. S.; Eliott, G. J.; Sedgwick, R. D.; Tyler, A. M. Anal. Chem. 1982, 54, 645a-655a.

8. McNeal, C. J. Mass Spectrometry in the Analysis of Large Molecules; Wiley: New York, 1986.

9. Fenn, J. B.; Mann, M.; Meng, C. K.; Whitehouse, C.; Wong, S.-F. Science 1989, in press.

10. Loo, J. A.; Udseth, H. R.; Smith, R. D. Anal. Biochem. 1989, $179,404-412$.

11. McLafferty, F. W., Ed. Tandem Mass Spectrometry; Wiley: New York, 1983.

12. Busch, K. L.; Glish, G. L.; McLuckey, S. A. Mass Spectrometry/Mass Spectrometry; VCH: Deerfield, FL, 1988.

13. McLuckey, S. A.; Glish, G. L.; Asano, K. G.; Grant, B. C. Anal. Chem. 1988, 60, 2220-2227.

14. Buchanan, M. V., Ed. Fourier Transform Mass Spectrometry; American Chemical Society: Washington, DC, 1987.

15. Freiser, B. S. In Techniques for Study of Ion Molecule Reactions; Ferrar, J. M.; Saunders, W. H., Jr., Eds.; Wiley: New York, 1988; pp 61-118.

16. Wilkins, C. L.; Chowdhury, A. K.; Neuwaysir, L. M.; Coates, M. L. Mass Spectrom. Rev. 1989, 8, 67-92.

17. McLafferty, F. W.; Stauffer, D. B. Wiley/NBS Regist ry of Mass Spectral Data; Wiley: New York, 1989

18. Gohlke, R. S. Anal. Chem. 1959, 31, 535.

19. Thomson, J. J. Rays of Positive Electricity and Their Application to Chemical Analyses; Longmans-Green: London, 1913; p 32.

20. Aston, F. W. Isotopes; Arnold: London, 1922; p 29.

21. Loo, J. A.; Barinaga, C. J.; Edmonds, C. G.; Udseth, H. R.; Smith, R. D. Presented at the ASMS Meeting, Miami Beach, FL, May 1989; paper TPA36.

22. Covey, T. R.; Sushan, B. I.; Bonner, R. F.; Henion, J. Presented at the ASMS Meeting, Miami Beach, FL, May 1989; paper ROE3: 15 .

23. Danis, P. O.; Wesdemiotis, C.; McLafferty, F, W, J. Am. Chem. Soc, 1983, 105, 7454-7456.

24. Wesdemiotis, C.; McLafferty, F. W. Chem. Rev. 1987, 87, 485-500.

25. Holmes, J. L. Mass Spectrom. Rev. 1989, 8, 513-539.

26. McLafferty, F. W. Science, in press.

27. Tomer, K. B.; Crow, F. W.; Gross, M. L. J. Am. Chem. Soc. 1983, 105, 5487-5488.

28. Feng, R.; Wesdemiotis, C; Zhang, M.-Y.; Marchetti, M; McLafferty, F. W. J. Am. Chem. Soc. 1989, 111, 1986-1991.

29. Henry, K. D.; Williams, E. R.; Wang, B.-H.; McLafferty, F.
W.; Shabanowitz, J.; Hunt, D. F. Proc. Natl. Acad. Sci. U.S.A. 1989, 86, 9075-9078.

30. Boettger, H. G.; Griffin, C. E.; Norris, D. D. ACS Symp. Ser. 1979, 102, 291-318.

31. Amster, I. J.; McLafferty, F. W.; Castro, M. E.; Russell, D. H.; Cody, R. B., Jr.; Ghaderi, S. Anal. Chem. 1986, 58, 483-485.

32. McLafferty, F. W.; Stauffer, D. B.; Loh, S. Y.; Williams, E. R. Anal. Chem. 1987, 59, 2212-2213,

33. Williams, E. R.; Loh, S. Y.; McLafferty, F. W. J. Am. Chem. Soc., submitted.

34. Chen, L.; Wang, T. C.; Ricca, T. L.; Marshall, A. G. Anal. Chem. 1987, 59, 449-454.

35. Stenhagen, E.; Abrahamsson, S.; McLafferty, F. W. Registry of Mass Spectral Data; Wiley-Interscience: New York, 1969, 1974.

36. Salton, G. Dynamic Information and Library Processing; Prentice-Hall: Englewood Cliffs, NJ, 1975.

37. McLafferty, F. W.; Hertel, R. H.; Villwock, R. D. Org. Mass Spectrom. 1974, 9, 690 .

38. McLafferty, F. W.; Stauffer, D. B. J. Chem. Inf. Comput. Sci. 1985, 25, 245-252.

39. McLafferty, F. W. Anal. Chemt. 1977, 49, 1441-1443.

40. Kwok, K.-S.; Venkataraghavan, R.; McLafferty, F. W. J. Am. Chem. Soc. 1973, 95, 4185

41. Rosenstock, H. M.; Wallenstein, M. B.; Wahrhaftig, A. L.; Eyring, H. Proc. Natt. Acad. Sci. U.S.A. 1952, 38, 667.

42. McLafferty, F. W.; Wachs, T.; Lifshitz, C.; Innorta, G.; Irving, P. J. Am. Chem. Soc. 1970, 92, 6867-6880.

43. Rylander, P. N.; Myerson, S.; Grubb, H, M. J. Am. Chem. Soc. $1957,79,842$.

44. McLafferty, F. W. Anal. Chem. 1956, 28, 306.

45. MeLafferty, F. W. Anal. Chen. 1959, 31, 82.

46. Olah, G. A.; Schleyer, P. von R. Carbonium Ions; WileyInterscience: New York, 1968.

47. Roth, H. D. . Ed. Structure and Reactivity of Organic Radical lons, Tetrahedron 1986, 42, 6097-6349.

48. Attina, M.; Cacace, F.; di Marzio, A. J. Am. Chem. Soc. 1989, $111,6004-6008$.

49. Saykally, R. J. Science 1988, 239, 157-161.

50. Gill, P. M. W.; Radom, L. J. Am. Chem. Soc. 1988, 110, 5311-5314.

51. Turecek, F.; McLafferty, F. W. J. Am. Chem. Soc. 1984, 106, 2525-2528.

52. Allison, C. E.; Stringer, M. B.; Bowie, J. H.; Derrick, P. J. J. Am. Chem. Soc. 1988, 110, 6291-6297.

53. Turecek, F.; Drinkwater, D. E.; McLafferty, F. W. J. Am. Chem. Soc., accepted.

54. Adams, J.; Gross, M. L. J. Am. Chem. Soc. 1989, 111, 435-440.

55. Zhang, M.-Y.; Wesdemiotis, C.; Marchetti, M.; Danis, P. O.; Ray, J. C., Jr.; Carpenter, B. K.; McLafferty, F. W. J. Am. Chem. Soc. 1989, 111, 8341-8346.

56. Feng, R.; Wesdemiotis, C.; Baldwin, M. A.; McLafferty, F. W. Int. I. Mass Spectrom. Ion Processes 1988, 86, 95-107.

57. Turecek, F.; Drinkwater, D. E.; McLafferty, F. W. J. Am Chem. Soc. 1989, 111, 7696-7701.

58. Wesdemiotis, C.; Leyh, B.; Fura, A.; McLafferty, F. W. J. Am. Chem. Soc., submitted. 